\title{
Oxidative Membrane Damage and the Resulting Alteration in the Membrane Lipid Bilayer Structure of Human Erythrocytes Caused by Radical-Forming Oxidants
}

\author{
Takashi SAto, ${ }^{1}$ Akira TAmura, ${ }^{2}$ Isao KAwAGUChI, ${ }^{1}$ \\ and Tatsuzo FUJII ${ }^{1, *}$ \\ ${ }^{1}$ Department of Biochemistry, Kyoto Pharmaceutical University, \\ Yamashina-ku, Kyoto 607, Japan \\ ${ }^{2}$ Department of Food and Nutrition, Faculty of Home Economics, \\ Chukyo Women's University, Ohbu 474, Japan
}

(Received March 11, 1992)

\begin{abstract}
Summary Treatment of washed human erythrocytes for a short time (up to $2 \mathrm{~h}$ ) with 75 or $100 \mathrm{~mm} 2,2^{\prime}$-azo-bis(2-amidinopropane) dihydrochloride (AAPH), a water-soluble, radical-forming oxidant, induced considerable oxidation of the membrane protein $\mathrm{SH}$ groups, without any detectable formation of lipid peroxide from the membrane lipid. These cells became susceptible to the action of pancreatic phospholipase $A_{2}$, and the asymmetric distribution of their membrane aminophospholipids was partially lost, accompanied by a reduced activity of the aminophospholipid translocase of the membrane. In contrast, treatment of the erythrocytes with $t$-butylhydroperoxide ( $t$-BHP), a lipid-soluble, radicalforming oxidant, caused rapid and intensive lipid peroxidation, but $\mathrm{SH}$ oxidation to a lesser extent than that achieved by AAPH. In these cells, the membrane phospholipid asymmetry was well maintained, although the aminophospholipid translocase activity was reduced. These results suggest that AAPH might oxidize both the aminophospholipid translocase of the membrane and the membrane skeletal proteins responsible for maintenance of the asymmetric phospholipid distribution, resulting in loss of the asymmetry, and that $t$-BHP causes formation of peroxides from the membrane phospholipids, which might affect aminophospholipid translocase only.
\end{abstract}

Key Words: erythrocyte, membrane damage, membrane lipid bilayer, oxygen radical, radical-forming oxidant

\footnotetext{
${ }^{*}$ To whom correspondence should be addressed.
} 
Erythrocytes have been used extensively for studies on oxidative damage of the plasma membrane of cells, because their plasma membrane as the sole membrane system in the cells is well characterized and also because they contain a large quantity of iron in the form of hemoglobin, which transition element is effective to induce chain reactions of lipid peroxidation [1]. It was already reported that exposure of erythrocytes to hydrogen peroxide, active oxygen radicals, or lipid peroxides brings about reduced activity of some membrane-bound enzymes [2,3]; opening of pores in the membrane, which permits passage of certain water-soluble, low-molecular weight substances [4]; enhanced phagocytosis by macrophages [5]; and finally hemolysis [6]. In some instances, even when lipid peroxidation by these oxidants was prevented by the addition of anti-oxidants, there still occurred some membrane damages, such as hemolysis and polymerization of certain membrane proteins [7]. These results suggest that lipid peroxidation may not necessarily be the sole cause of the structural as well as functional disturbances in the membrane due to oxidative damage.

On the other hand, the well-characterized asymmetric distribution of phospholipid classes in the membrane lipid bilayer of erythrocytes [8], with exclusive localization of phosphatidylserine (PS) in the inner leaflet and the relative abundance of choline-phospholipids in the outer leaflet, could be modified or lost upon treatment of the erythrocytes with oxidizing agents such as diamide [9], phenylhydrazine [10], and hydrogen peroxide [11, 12]. Such asymmetric distribution of membrane phospholipids was already reported to be maintained by an enzyme called aminophospholipid translocase [13], which transports aminophospholipids exclusively from the outer to the inner leaflet of the membrane lipid bilayer in an ATP-dependent way, and/or by direct interaction of certain skeletal proteins with the phospholipid bilayer [9]. Therefore, any damage to these membrane components is likely to result in modification or loss of the asymmetric distribution.

In the present study, effects of some radical-forming oxidants on the state of the membrane lipid bilayer of intact human erythrocytes were studied. Especially, attempts were made to clarify their possible inhibitory effects on the aminophospholipid translocase to alter the asymmetric distribution of the membrane phospholipids, thus affecting the bilayer structure. The oxidants used were a watersoluble radical former, 2,2'-azo-bis (2-amidinopropane) dihydrochloride (AAPH), which does not require any transition metal ion for the radical formation [14], and a lipid-soluble radical former, $t$-butylhydroperoxide ( $t$-BHP), which is often used as a model compound of lipid peroxide [3].

\section{MATERIALS AND METHODS}

Materials. Main reagents used and their sources shown in parentheses were as follows: 2,2'-azo-bis(2-amidinopropane) dihydrochloride (AAPH, Wako Pure Chemical Industries, Ltd., Osaka); $t$-butylhydroperoxide ( $t$-BHP), didecanoylphosphatidylcholine (DDPC), and cytidine monophosphomorpholidate (Sigma 
Chemical Co., St. Louis, MO); dipalmitoyl-phosphatidylcholine (DPPC, Nippon Oil \& Fat Co., Tokyo); butylated hydroxytoluene (BHT), diamide, and dithiothreitol (Nacalai Tesque, Inc., Kyoto); pancreatic and bee venom phospholipase $\mathrm{A}_{2}$, and phospholipase D from Streptomyces chromofuscus (Boehringer Mannheim $\mathrm{GmbH}$, Mannheim, Germany); ${ }^{14} \mathrm{C}-\mathrm{CH}_{3} \mathrm{I}$ and ${ }^{14} \mathrm{C}$-L-serine (Amersham International, Buckinghamshire, England).

Preparation of erythrocyte suspension and the membrane ghost. Erythrocytes were separated from fresh human citrate-phosphate-dextrose blood (given by courtesy of Kyoto Red Cross Blood Center) and washed 3 times with isotonic Hepes buffer (10 mm Hepes, $150 \mathrm{~mm} \mathrm{NaCl}$ [pH 7.4]; HBS) and suspended in the same buffer. Membrane ghosts were prepared from these washed erythrocytes by the method of Dodge et al. [15] with $20 \mathrm{~mm}$ phosphate buffer. The membrane protein content was determined by the method of Lowry et al. [16].

Treatment of erythrocytes with radical-forming oxidant or diamide. To the erythrocyte suspension (hematocrit value $10 \%$; $\mathrm{Ht}$ ), or the ghost suspension $(0.5 \mathrm{mg}$ protein $/ \mathrm{ml}$ ) in the presence of $50 \mu \mathrm{M} \mathrm{FeSO}_{4}$, was added an equal volume of various concentrations of AAPH solution in HBS, or $0.5 \%(\mathrm{v} / \mathrm{v})$ of $t$-BHP solution in ethanol. The mixture was incubated at $37^{\circ} \mathrm{C}$ for a certain period of time, and the reaction was stopped by the addition of $0.15 \mathrm{~mm}$ BHT.

Washed erythrocytes (Ht 10\%) were treated for $1 \mathrm{~h}$ with $5 \mathrm{~mm}$ diamide solution in HBS containing $10 \mathrm{~mm}$ glucose and washed with HBS. A portion of these erythrocytes was further treated with $5 \mathrm{mM}$ dithiothreitol in HBS containing $10 \mathrm{~mm}$ glucose and washed with HBS.

Treatment of erythrocytes with phospholipase $A_{2}$. The erythrocytes treated as above and then washed, or intact erythrocytes, were suspended in HBS containing $5 \mathrm{mM} \mathrm{CaCl}_{2}$. They were then incubated with pancreatic phospholipase $\mathrm{A}_{2}(15$ $\mathrm{IU} / \mathrm{ml})$ at $37^{\circ} \mathrm{C}$ for $30 \mathrm{~min}$, or with bee venom phospholipase $\mathrm{A}_{2}(12 \mathrm{IU} / \mathrm{ml})$ at $37^{\circ} \mathrm{C}$ for $35 \mathrm{~min}$. The reaction was stopped by the addition of $10 \mathrm{~mm}$ EDTA, and the phospholipid class composition was determined as described already [17].

Synthesis of radioactive phospholipids

(A) ${ }^{14}$ C-Labeled didecanoyl-phosphatidylcholine (DDPC). ${ }^{14} \mathrm{C}$-Labeled DDPC was prepared by the method of Stoffel [18] from DDPC. Briefly, DDPC was demethylated, and the choline moiety was labeled with ${ }^{14} \mathrm{C}_{-} \mathrm{CH}_{3} \mathrm{I}(52 \mathrm{mCi} /$ mmol). The labeled product was then purified by thin-layer chromatography.

(B) ${ }^{14}$ C-Labeled didecanoyl-phosphatidylserine (DDPS). Cytidine diphosphate dicaprin was synthesized from didecanoyl-phosphatidic acid and cytidine monophosphomorpholidate. Didecanoyl-phosphatidic acid was prepared by the enzymatic cleavage of DDPC by phospholipase D from Streptomyces chromofuscus. Phosphatidylserine synthetase was prepared from Escherichia coli according to the method of Ishinaga and Kito [19].

Cytidine diphosphate dicaprin $(4.5 \mu \mathrm{mol})$ and L-serine $(1.23 \mu \mathrm{mol})$ were sonicated for $1 \mathrm{~min}$ in $1.5 \mathrm{ml}$ of medium containing $15 \mathrm{mM} \mathrm{MgCl}_{2}, 0.5 \mathrm{mM}$ dithiothreitol, $1.0 \mathrm{~mm}$ hydroxylamine $0.1 \%$ Triton $\mathrm{X}-100$, and $33 \mathrm{~mm}$ phosphate buffer,

Vol. 12, No. 3, 1992 
$\mathrm{pH}$ 7.1. Phosphatidylserine synthetase $(5 \mathrm{mg}$ protein $/ \mathrm{ml}$ reaction mixture) and 15 $\mu \mathrm{Ci}$ (ca. $0.27 \mu \mathrm{mol})$ of ${ }^{14} \mathrm{C}$-L-serine $(56 \mathrm{mCi} / \mathrm{mmol})$ were added to the mixture, which was then incubated at $30^{\circ} \mathrm{C}$ for $30 \mathrm{~min}$. The reaction was stopped by the addition of $10 \mathrm{mM}$ EDTA, and the DDPS produced was extracted with chloroform-methanol $(2: 1)$ solution and purified by thin-layer chromatography.

Determination of translocation of added medium-chain phospholipids from the outer to the inner leaflet of the membrane lipid bilayer of erythrocytes [20]. Erythrocyte suspension (Ht 4\%) was treated with $10 \mu \mathrm{M}$ DDPS or DDPC, containing a trace amount of corresponding ${ }^{14} \mathrm{C}$-labeled phospholipid, at $37^{\circ} \mathrm{C}$ for various times. The added phospholipid remaining in the outer leaflet of the membrane lipid bilayer was removed by washing of the cells twice with a cold dipalmitoylphosphatidylcholine (DPPC)-liposome suspension, prepared by sonication of 0.1 $\mathrm{mm}$ DPPC, $0.1 \mathrm{~mm}$ cholesterol, $0.1 \%$ bovine serum albumin, and $10 \mathrm{~mm}$ glucose in HBS, and then washed with $150 \mathrm{~mm} \mathrm{NaCl}$. The residual radioactivity in these cells was measured with a liquid scintillation counter (LSC-1000, Aloka, Tokyo).

The amount of radioactivity determined on the erythrocytes washed in the same way as above immediately after addition of the labeled phospholipid (this is taken as the amount of the added phospholipid not extractable by the liposome washes) was subtracted from the above-mentioned residual radioactivity of the treated cells. The difference was taken as the amount of the labeled phospholipid translocated from the outer to the inner leaflet of the membrane lipid bilayer in the course of the experiment, and expressed as the amount per fixed number of cells.

Determination of lipid peroxides. Lipid peroxide formed in the erythrocyte membrane by treatments with the oxidants was determined by the method of Ohkawa et al. [21], after the erythrocyte specimen had been deproteinized with $8 \%$ trichloroacetic acid, and expressed as the thiobarbituric acid reaction product (TBA-RP).

Determination of $\mathrm{SH}$ content of erythrocyte membrane proteins. Membrane $\mathrm{SH}$ was determined by the method of Ellman [22].

\section{RESULTS}

Treatment of washed erythrocytes with 100 or $75 \mathrm{~mm}$ AAPH for up to $1-2 \mathrm{~h}$ did not induce any appreciable formation of lipid peroxide in terms of the amount of TBA-RP formed, as shown in Fig. 1A. With $100 \mathrm{mM} \mathrm{AAPH,} \mathrm{the} \mathrm{treatment} \mathrm{for}$ more than $3 \mathrm{~h}$ caused considerable formation of lipid peroxides. In contrast, similar treatment with 1 or $3 \mathrm{~mm} t$-BHP resulted in the immediate formation of TBA-RP, and the amount formed was dependent on the concentration of the oxidant used (Fig. 1B). Such lipid peroxidation of the membrane lipid by AAPH and $t$-BHP was completely inhibited by the addition of $1 \mathrm{~mm}$ uric acid and $0.1 \mathrm{~mm}$ butylated hydroxytoluene (BHT), respectively. Although no data are shown here, the prolonged treatment with AAPH caused slight hemolysis, which occurred almost in parallel with the lipid peroxide formation. The $t$-BHP caused no 


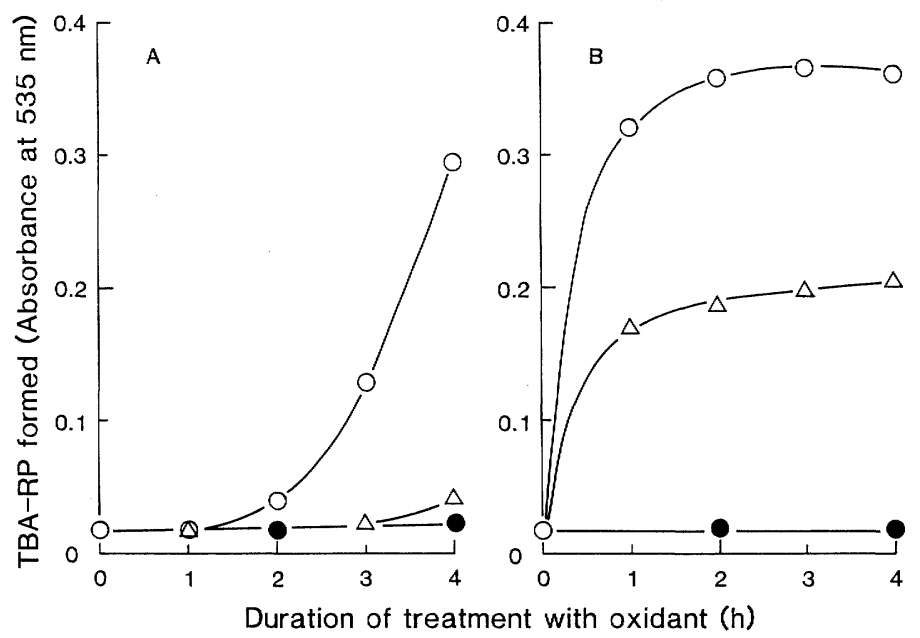

Fig. 1. Peroxidation of membrane lipids of washed erythrocytes by treatment with a radical-forming oxidant, AAPH or $t$-BHP. (A) Washed erythrocytes in suspension ( $\mathrm{Ht}$ $10 \%$ ) were treated at $37^{\circ} \mathrm{C}$ for $0-4 \mathrm{~h}$ with $100 \mathrm{~mm} \mathrm{AAPH}(\bigcirc), 75 \mathrm{~mm}$ AAPH $(\triangle)$, or 100 mM AAPH in the presence of $1 \mathrm{~mm}$ uric acid $(\bullet)$; and the amount of lipid peroxide formed was determined by the TBA method. (B) Washed erythrocytes were treated similarly with $3 \mathrm{~mm} t$-BHP $(\bigcirc), 1 \mathrm{~mm} t$-BHP $(\triangle)$, or $3 \mathrm{~mm} t$-BHP in the presence of 0.1 mм BHT (๑); and the lipid peroxide formed was quantified.

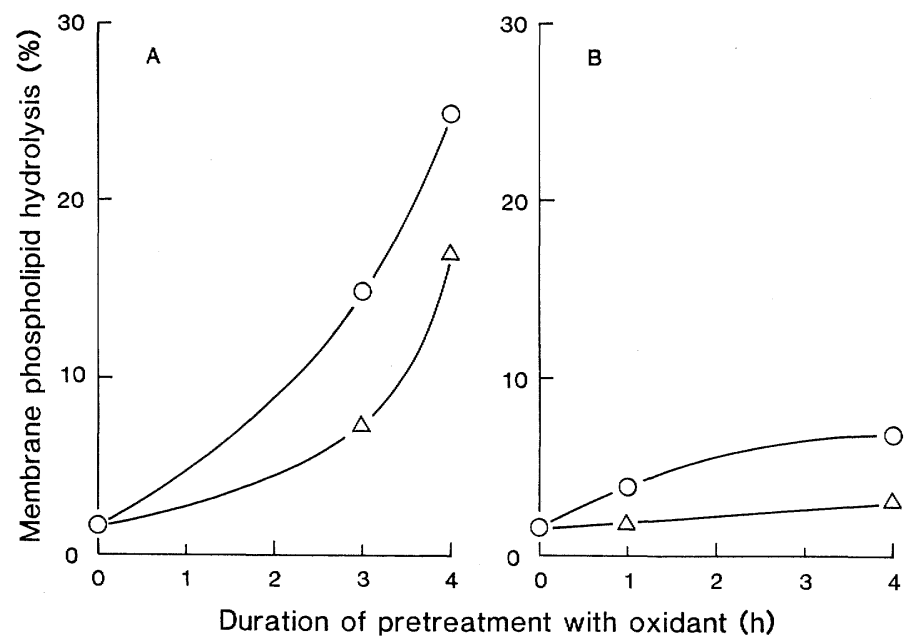

Fig. 2. Hydrolysis by pancreatic phospholipase $\mathrm{A}_{2}$ of the membrane phospholipids of washed erythrocytes pretreated with a radical-forming oxidant, AAPH or $t$-BHP. Washed erythrocytes in suspension ( $\mathrm{Ht} 10 \%$ ), which had been pretreated with $75 \mathrm{mM}$ AAPH (in A) or $1 \mathrm{~mm} t$-BHP (in B) at $37^{\circ} \mathrm{C}$ for $0-4 \mathrm{~h}$ and then washed to remove the excess oxidant, were treated with pancreatic phospholipase $A_{2}(15 \mathrm{IU} / \mathrm{ml})$ in the presence of $5 \mathrm{~mm} \mathrm{CaCl} 2$ at $37^{\circ} \mathrm{C}$ for $30 \mathrm{~min}$. Membrane phospholipids in the cells before and after the enzyme treatment were extracted and quantified; and the \% hydrolysis of PC $(O)$ and of PE $(\triangle)$ was calculated therefrom.

Vol. 12, No. 3, 1992 
hemolysis at any reagent concentration or any treatment time tested.

Pretreatment of washed erythrocytes, which originally are quite resistant to hydrolytic action of pancreatic phospholipase $\mathrm{A}_{2}$, with $75 \mathrm{~mm}$ AAPH for $3-4 \mathrm{~h}$ resulted in significant hydrolysis of the membrane phospholipids, phosphatidylcholine (PC) and phosphatidylethanolamine (PE), by this enzyme. The hydrolysis of either phospholipid increased with prolongation of the time of pretreatment with the oxidant (Fig. 2A). Similar treatment with $1 \mathrm{mM} t$-BHP for up to $4 \mathrm{~h}$ caused only slight hydrolysis of the membrane $\mathrm{PC}$ and practically no hydrolysis of the PE (Fig. 2B).

In order to know the distribution of each glycerophospholipid class in the lipid bilayer of the membrane of the intact and oxidant-treated erythrocytes, we subjected the phospholipids under non-hemolytic conditions to hydrolysis by bee venom phospholipase $A_{2}$, which is reported to hydrolyze most of the glycerophospholipids located in the outer leaflet of the bilayer. In intact erythrocytes, the enzyme treatment brought about hydrolysis of about 70,6, and $0 \%$ of the total PC, PE, and PS present in the membrane, respectively (Fig. 3). Treatment of the cells with $75 \mathrm{mM}$ AAPH induced a remarkable increase in the hydrolysis of PE and PS, but effected only a very slight decrease in the PC hydrolysis. Upon a 4-h treatment, 30 and $20 \%$ of the PE and PS, respectively, were hydrolyzed by this enzyme (Fig. $3 \mathrm{~A}$ ). Because practically no PS, and only about $20 \%$ of the total PE, is present in

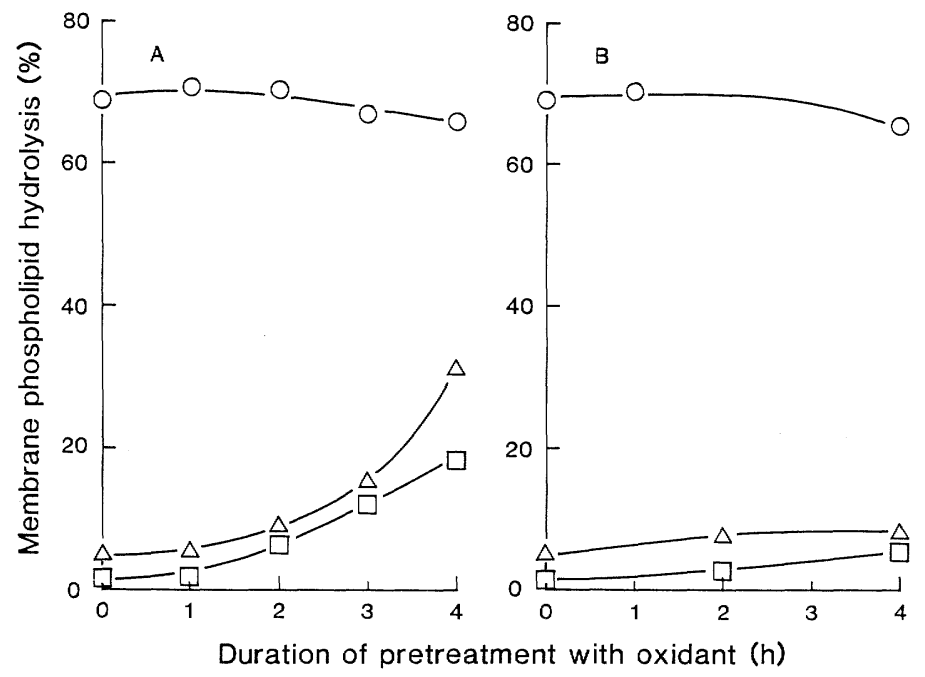

Fig. 3. Hydrolysis by bee venom phospholipase $A_{2}$ of the membrane phospholipids of washed erythrocytes pretreated with a radical-forming oxidant, AAPH or $t$-BHP. Washed erythrocytes in suspension ( $\mathrm{Ht} 10 \%$ ), which had been pretreated with $75 \mathrm{~mm}$ AAPH (in A) or $1 \mathrm{~mm} t$-BHP (in B) at $37^{\circ} \mathrm{C}$ for $0-4 \mathrm{~h}$ and then washed to remove the excess oxidant, were treated with bee venom phospholipase $A_{2}(12 \mathrm{IU} / \mathrm{ml})$ at $37^{\circ} \mathrm{C}$ for 35 min. Membrane phospholipids in the cells before and after the enzyme treatment were extracted and quantified; and the \% hydrolysis of PC $(\bigcirc)$ PE $(\triangle)$, and PS $(\square)$ was calculated therefrom. 
the outer leaflet of the intact cells [8], such a result may mean that the original asymmetric distribution of these aminophospholipids was lost, at least partially, by such a treatment; while localization of the PC in the outer leaflet was not appreciably influenced. In contrast, treatment of the erythrocytes with $1 \mathrm{mM} t$-BHP even for as long as $4 \mathrm{~h}$ caused only a very slight increase in the PE and PS hydrolysis by the bee venom phospholipase $\mathrm{A}_{2}$ (Fig. 3B).

In order to uncover the possible cause of the loss of the original asymmetric distribution of the membrane aminophospholipids due to the oxidant treatment, we investigated the effect of the oxidant on the aminophospholipid translocase activity in the membrane, which enzyme is believed to be one of the possible factors responsible for maintaining the phospholipid asymmetry in the membrane lipid bilayer [13]. The translocase activity was measured by determining the rate of translocation of an added medium-chain phospholipid from the outer to the inner leaflet of the membrane lipid bilayer of washed erythrocytes after its incorporation. ${ }^{14} \mathrm{C}$-Labeled PS having two identical decanoyl fatty acyl chains (DDPS) was employed as the probe. Such phospholipids with medium-length fatty acyl chains were already proved to be easily incorporated into the lipid bilayer immediately after addition to the suspending medium [20]. A preliminary experiment indicated that upon incubation of washed erythrocytes at $37^{\circ} \mathrm{C}$ for $30 \mathrm{~min}$ in the

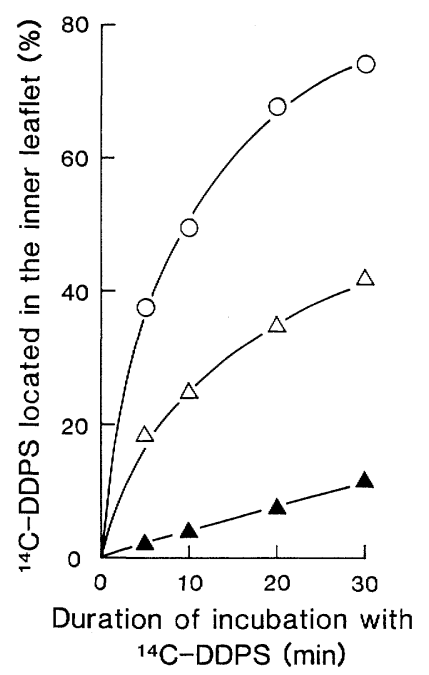

Fig. 4. Influence of treatment of washed erythrocytes with a SH-group oxidant, diamide, on translocation of exogenously-added ${ }^{14} \mathrm{C}$-DDPS from the outer to the inner leaflet of the membrane lipid bilayer. Intact erythrocytes $(O)$, the erythrocytes treated with $5 \mathrm{~mm}$ diamide for $1 \mathrm{~h}(\mathbf{\Delta})$, or the cells first treated with $5 \mathrm{~mm}$ diamide for $1 \mathrm{~h}$ and then with $5 \mathrm{~mm}$ dithiothreitol for $1 \mathrm{~h}(\triangle)$ were incubated with $10 \mu \mathrm{M}{ }^{14} \mathrm{C}$-DDPS at $37^{\circ} \mathrm{C}$ for $5-30$ $\min$. The labeled phospholipid present in the outer leaflet of the membrane lipid bilayer was extracted with a liposome suspension; and the remaining radioactivity in the cells, which represents the labeled lipid translocated into the inner leaflet of the lipid bilayer, was determined. 
presence of ${ }^{14} \mathrm{C}$-DDPS about $75 \%$ of this phospholipid was translocated into the inner leaflet (Fig. 4). Previous treatment of the cells either with $100 \mathrm{mM} \mathrm{AAPH}$ or with $1 \mathrm{mM} t$-BHP similarly reduced the initial rate of the PS translocation by about $30 \%$ (Fig. 5). To further confirm that the reduced aminophospholipid translocase activity is one of the factors responsible for inducing the loss of phospholipid asymmetry in the membrane, we next checked the effect of $5 \mathrm{~mm}$ diamide, an oxidant known to oxidize $\mathrm{SH}$ groups of membrane proteins and to abolish the asymmetric distribution of aminophospholipids in the membrane lipid bilayer [9], on the DDPS translocation rate. Actually the treatment caused a drastic decrease in the rate of DDPS translocation, which could be partially reversed by further treatment with dithiothreitol (Fig. 4).

We also observed that the very slow rate of trans-bilayer movement of DDPC, which is not transported by the aminophospholipid translocase, was not inhibited, but rather enhanced, by any treatment with AAPH, $t$-BHP or diamide (data not shown).

Considering the fact reported above that the $75 \mathrm{~mm}$ AAPH treatment did not give any detectable formation of lipid peroxide, at least up to $3 \mathrm{~h}$, and the experiments of Figs. 3 and 5 were performed under such a condition, a possible effect of the radical-forming oxidant on $\mathrm{SH}$ groups of the membrane proteins was examined. Treatment of intact erythrocytes with $75 \mathrm{~mm}$ AAPH or $1 \mathrm{~mm} t$-BHP for 0.5-3 h resulted in time-dependent decrease in the membrane SH content (Fig. 6).

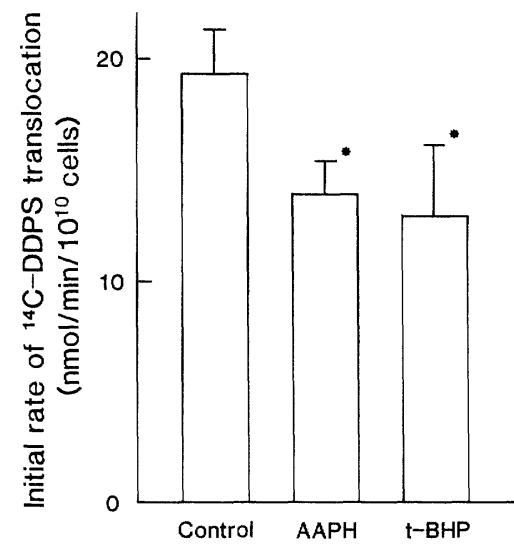

Fig. 5. Influence of treatment of washed erythrocytes with a radical-forming oxidant, AAPH or $t$-BHP, on translocation of exogenously-added ${ }^{14} \mathrm{C}$-DDPS from the outer to the inner leaflet of the membrane lipid bilayer. Intact erythrocytes (left column), those treated with $100 \mathrm{~mm} \mathrm{AAPH}$ for $2 \mathrm{~h}$ (center column), or those treated with $1 \mathrm{~mm} t$-BHP for $2 \mathrm{~h}$ (right column) were incubated with ${ }^{14} \mathrm{C}$-DDPS, and the amount of the labeled phospholipids translocated from the outer to the inner leaflet of the membrane lipid bilayer was determined as described in the legend of Fig. 4. The initial rate of translocation for the first $5 \mathrm{~min}$ was calculated therefrom. Each bar represents mean $\pm \mathrm{SD}$ of 3 separate experiments performed in duplicate. Asterisk means significant difference with respect to control $(p<0.05)$. 


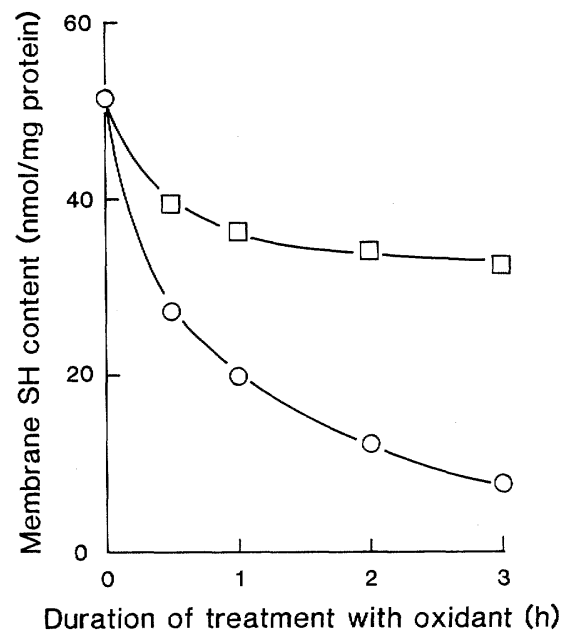

Fig. 6. Effect of treatment of washed erythrocytes with a radical-forming oxidant, AAPH or $t$-BHP, on $\mathrm{SH}$ content of the membrane proteins. Membrane ghosts, prepared from intact erythrocytes, were treated with $75 \mathrm{~mm} \mathrm{AAPH}(O)$ or $1 \mathrm{~mm} t-\mathrm{BHP}(\square)$ at $37^{\circ} \mathrm{C}$ for $0-3 \mathrm{~h}$, and the $\mathrm{SH}$ content was then determined.

The oxidizing effect of AAPH on the protein SH was more drastic than that of $t$-BHP. The treatment with $75 \mathrm{~mm}$ AAPH for $3 \mathrm{~h}$ resulted in a decrease in the total SH content by about $80 \%$, while that with $1 \mathrm{~mm} t$-BHP for $3 \mathrm{~h}$ brought about a decrease of only about $30 \%$.

\section{DISCUSSION}

AAPH is a water-soluble compound that can be degraded by heat to form a radical in aqueous solution, and this radical is thought to attack oxidatively the plasma membrane of intact cells from its outside [6]. Although prolonged exposure of human erythrocytes to this agent may cause hemolysis [6], exposure for a short duration, as attempted in the present study to detect membrane perturbation under a non-hemolytic condition, neither caused hemolysis nor lipid peroxidation.

$t$-BHP is a lipid-soluble radical former that can be incorporated into the membrane lipid bilayer of intact erythrocytes when added to a suspension of such cells and becomes an alkoxyl radical (BuO.) in the presence of hemoglobin iron [3]. This radical induces lipid peroxidation of the membrane.

It has been reported already that membrane phospholipids of intact erythrocytes are resistant to attack by pancreatic phospholipase $A_{2}$ but that they become susceptible to the hydrolytic action of this enzyme if the packing of the phospholipids is loosened [23] or when certain perturbation of the outer leaflet of the lipid bilayer is induced by treatment with drugs or some other agents [24]. The significant hydrolysis by this enzyme of the membrane phospholipids PC and PE in erythrocytes previously treated with AAPH, as revealed in the present study, is 
therefore considered to be due to lipid bilayer perturbation effected by the AAPH radicals formed. Available evidence showing that hydrogen peroxide-treated erythrocytes became susceptible to the phagocytic action of macrophages due to loosened packing of the outer layer phospholipids of the membrane under the $\mathrm{H}_{2} \mathrm{O}_{2}$ attack may also support such an idea [5]. Our results showing that such an effect of $75 \mathrm{~mm}$ AAPH appeared even when formation of lipid peroxide was not yet observed and also that another oxidant, $t$-BHP, which produced abundant lipid peroxides, did not exert such an action, suggest that the observed perturbation in the membrane lipid bilayer brought by AAPH might be not due to the action of lipid peroxides secondarily formed, but rather due to the direct oxidizing action of the radical, probably on the membrane proteins.

Asymmetric distribution of phospholipids in the erythrocyte membrane lipid bilayer is a well-known fact, with predominance of choline-containing phospholipids present in the outer leaflet and with only 20 and $0 \%$ of PE and PS, respectively, present in this leaflet [8]. These latter aminophospholipids, which were originally not hydrolyzed by exogenously-added bee venom phospholipase $\mathrm{A}_{2}$, became hydrolyzed by this enzyme after the cells had been treated with AAPH, as shown in Fig. 3. Upon treatment of the cells with $75 \mathrm{~mm} \mathrm{AAPH}$ for $4 \mathrm{~h}$, about 30 and $20 \%$ of the total PE and PS present, respectively, were hydrolyzed, and this fact probably means actual transfer of some part of these aminophospholipids from the inner to the outer leaflet of the bilayer as a result of oxidative damage to the membrane by the radical action, resulting in partial loss of their asymmetric distribution, as already reported in the case of hydrogen peroxide- [11] or phenylhydrazine- [10] treated erythrocytes. It is interesting to note that such an asymmetry loss was caused by the radical at the point when no appreciable lipid peroxidation is yet induced in the membrane by the radical action (Fig. 1). In contrast, another radical-former, $t$-BHP, did not induce such a loss of phospholipid asymmetry even after its action on the same cells for as long as $4 \mathrm{~h}$, by which time considerable lipid peroxidation had already occurred.

The above-mentioned asymmetric distribution of aminophospholipids in the lipid bilayer is considered to be due to their strong interaction with membrane skeletal proteins such as spectrin, and/or activity of the enzyme aminophospholipid translocase, which transports specifically certain aminophospholipids from the outer to the inner leaflet of the bilayer in an energy-dependent manner. Therefore, we measured the activity of this enzyme in the radical-treated erythrocytes by determining the rate of translocation from the outer to the inner leaflet of labeled PS with two identical medium-length fatty acyl chains, DDPS. Treatment of the cells with either AAPH or $t$-BHP equally reduced the enzyme activity by $30-40 \%$, as compared with that in the untreated cells (Fig. 5).

The fact that such a translocation of the added DDPS is due to aminophospholipid translocase, a SH-containing enzyme, was confirmed by observation of the effect of diamide, an agent known to oxidize membrane protein $\mathrm{SH}$ groups to S-S and to inhibit this particular enzyme [25] (Fig. 6). The experiment in which 
reduction of such $\mathrm{S}-\mathrm{S}$ was caused by dithiothreitol, with the accompanying recovery of the enzyme activity, may further confirm this idea.

The results showing that the slow translocation rate of DDPC, which is not a substrate of this enzyme, was not inhibited by the treatments with the radicalforming oxidants or with diamide (data not shown), may also support the idea that their inhibitory effect on the DDPS translocation is due to their selective inhibitory effect on the enzyme.

The AAPH treatment brought about a more drastic decrease in the content of membrane protein $\mathrm{SH}$ groups than did $t$-BHP treatment (Fig. 6). This may mean that a considerable proportion of both the membrane and skeletal proteins were oxidized by AAPH. The fact that the membrane phospholipid asymmetry is lost, at least partially, in the AAPH-treated erythrocytes, but not in the $t$-BHP-treated cells, in spite of the fact that the aminophospholipid translocase in these cells was almost equally inhibited by the treatments with these radical-forming oxidants, may be explained by the different degree of oxidative damage by these oxidants to the membranous as well as skeletal proteins that are responsible for maintenance of the phospholipid asymmetry in the membrane.

\section{REFERENCES}

1. Chiu, D., Lubin, B., and Shohet, S.B. (1982): Peroxidative reactions in red cell biology, in Free Radicals in Biology, ed. by Pryor, W.A., Vol. 5, Academic Press, New York, pp. 115159.

2. Moore, R.B., Brummitt, M.L., and Mankad, V.N. (1989): Hydroperoxides selectively inhibit human erythrocyte membrane enzyme. Arch. Biochem. Biophys., 273, 527-534.

3. Van der Zee, J., Van Steveninck, J., Koster, J.F., and Dubbelman, T.M.A.R. (1989): Inhibition of enzymes and oxidative damage of red blood cells induced by $t$-butylhydroperoxide-derived radicals. Biochim. Biophys. Acta, 980, 175-180.

4. Heller, K.B., Poser, B., Haest, C.W.M., and Deuticke, B. (1984): Oxidative stress of human erythrocytes by iodate and periodate. Reversible formation of aqueous membrane pores due to SH-group oxidation. Biochim. Biophys. Acta, 777, 107-116.

5. Pradhan, D., Weiser, M., Lumley-Sapanski, K., Frazier, D., Kemper, S., Williamson, P., and Schlegel, R.A. (1990): Peroxidation-induced perturbations of erythrocyte lipid organization. Biochim. Biophys. Acta, 1023, 398-404.

6. Yamamoto, Y., Niki, E., Kamiya, Y., Miki, M., Tamai, H., and Mino, M. (1986): Free radical chain oxidation and hemolysis of erythrocytes by molecular oxygen and their inhibition by vitamin E. J. Nutr. Sci. Vitaminol, 32, 475-479.

7. Snyder, L.M., Fortier, N.L., Leb, L., McKenney, J., Trainor, J., Sheerin, H., and Mohandas, N. (1988): The role of membrane protein sulfhydryl groups in hydrogen peroxide-mediated membrane damage in human erythrocytes. Biochim. Biophys. Acta, 937, 229-240.

8. Zwaal, R.A., Loelofsen, B., and Colley, C.M. (1973): Localization of red cell membrane constituents. Biochim. Biophys. Acta, 300, 159-182.

9. Haest, C.W.M., Plasa, G., Kamp, D., and Deuticke, B. (1978): Spectrin as a stabilizer of the phospholipid asymmetry in the human erythrocyte membrane. Biochim. Biophys. Acta, 509, $21-32$.

10. Arduini, A., Stern, A., Storto, S., Belfiglio, M., Mancinelli, G., Scurti, R., and Federici, G. (1989): Effect of oxidative stress on membrane phospholipid and protein organization in human erythrocytes. Arch. Biochem. Biophys., 273, 112-120.

Vol. 12, No. 3, 1992 
11. Jain, S.K. (1984): The accumulation of malonyldialdehyde, a product of fatty acid peroxidation, can disturb aminophospholipid organization in the membrane bilayer of human erythrocytes. J. Biol. Chem., 259, 3391-3394.

12. Herrmann, A., and Devaux, P.F. (1990): Alteration of the aminophospholipid translocase activity during in vivo and artificial aging of human erythrocytes. Biochim. Biophys. Acta, 1027, 41-46.

13. Zachowski, A., Favre, E., Cribier, S., Herve, P., and Devaux, P.F. (1986): Outside-inside translocation of aminophospholipids in the human erythrocyte membrane is mediated by a specific enzyme. Biochemistry, 25, 2585-2590.

14. Videla, L.A., Caceres, T., and Lissi, E.A. (1988): Antioxidant capacity of desferrioxamine and ferrioxamine in the chemically-initiated lipid peroxidation of rat erythrocyte ghost membranes. Biochem. Intern., 16, 799-807.

15. Dodge, J.T., Mitchell, C., and Hanahan, D.J. (1963): The preparation and chemical characteristics of hemoglobin-free ghosts of human erythrocytes. Arch. Biochem. Biophys., 100, 119-130.

16. Lowry, O.H., Rosebrough, N.J., Farr, A.L., and Randall, R.J. (1951): Protein measurement with the folin phenol reagent. J. Biol. Chem., 193, 265-275.

17. Fujii, T., and Tamura, A. (1979): Asymmetric manipulation of the membrane lipid bilayer of intact human erythrocytes with phospholipase A, C or D induces a change in cell shape. J. Biochem., 86, 1345-1352.

18. Stoffel, W. (1975): Chemical synthesis of choline-labeled lecithins and sphingomyelins. Methods Enzymol, 35, 533-541.

19. Ishinaga, M., and Kito, M. (1974): Participation of soluble phosphatidylserine synthetase in phosphatidylethanolamine biosynthesis in Escherichia coli membrane. Eur. J. Biochem., 42, 483-487.

20. Fujii, T., Tamura, A., and Yamane, T. (1985): Trans-bilayer movement of added phosphatidylcholine and lysophosphatidylcholine species with various acyl chain lengths in plasma membrane of intact human erythrocytes. J. Biochem., 98, 1221-1227.

21. Ohkawa, H., Ohishi, N., and Yagi, K. (1979): Assay for lipid peroxides in animal tissues by thiobarbituric acid reaction. Anal. Biochem., 95, 351-358.

22. Ellman, G.L. (1959): Tissue sulfhydryl groups. Arch. Biochem. Biophys., 82, 70-77.

23. Demel, R.A., Geurts Van Kessel, W.S.M., Zwaal, R.F.A., Roelofsen, B., and Van Deenen, L.L.M. (1975): Relation between various phospholipase actions on human red cell membranes and the interfacial phospholipid pressure in monolayers. Biochim. Biophys. Acta, 406, 97-107.

24. Tamura, A., Moriwaki, N., and Fujii, T. (1983): Disturbing effect of cationic amphiphilic drugs on phospholipid asymmetry of the membrane lipid bilayer of human erythrocytes. Chem. Pharm. Bull., 31, 1692-1697.

25. Connor, J., and Schroit, A.J. (1988): Transbilayer movement of phosphatidylserine in erythrocytes: Inhibition of transport and preferential labeling of a 31000-dalton protein by sulfhydryl reactive reagents. Biochemistry, 27, 848-851. 